\title{
Comment on "volume-outcome relationship on survival and cost benefits in severe burn injury: a retrospective analysis of a Japanese nationwide administrative database" (Endo et al., Journal of Intensive Care 2019)
}

\author{
Akinori Osuka* (D), Daiki Miyao and Yuichi Kuroki
}

\begin{abstract}
This is a critical comment on the paper by Endo et al. on the volume-outcome relationship on survival and cost benefits in severe burn injury which addresses biases related to patient transfer and burn severity assessment.
\end{abstract}

Keywords: Burn, In-hospital mortality, Size of burn center

\section{Comment}

We read with interest the manuscript titled "Volume-outcome relationship on survival and cost benefits in severe burn injury: a retrospective analysis of a Japanese nationwide administrative database" published by Endo et al. in the Journal of Intensive Care in January 2019 [1]. The authors conclude that high burn patient volume was significantly associated with increased in-hospital mortality. We would like to offer some critical comments on the conclusions made from the results of this study.

First, in the methods section, the authors stated that they excluded patients who were transferred to another hospital within 3 days of admission. Further, Figure S7 shows that compared to Figure 2, in-hospital mortality is markedly increased in low-volume burn centers. Figure S7 shows the association between annual severe burn patient volume and the adjusted risk of in-hospital

\section{* Correspondence: ao1219@gmail.com}

Department of Trauma, Critical Care \& Burn Center, Japan Community Healthcare Organization Chukyo Hospital, 1-1-10 Sanjo, Minamiku, Nagoya, Aichi 457-8510, Japan

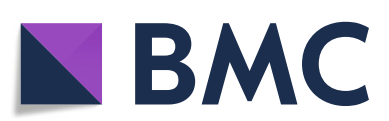

survival among patients who survived for more than 2 days after admission. If a low-volume burn center transfers severe burn patients who would have died within 2 days to a high-volume center, this could explain the differences between Figures 2 and S7. In other words, lowvolume centers care for patients with severe burns within 3 days who were not counted in their death toll because they were transferred to a different hospital, whereas high-volume centers care for patients with severe burns until the end, which increases their inhospital mortality rate.

Second, assessing the size of a burn has proven difficult. Physicians who are unfamiliar with burn sizing tend to overestimate it and underestimate it less often [2]. This can also contribute to a higher life-saving rate in low-volume centers.

In addition, it has been shown that the time until the death of patients with severe burns who survive the resuscitation period is more than 1 week [3]. Toxic shock syndrome, a known fatal complication, usually develops around 3 to 5 days after injury [4], and burn-induced 
sepsis usually develops 1 week after injury. Such late occurrence of sepsis is more specific to burn injuries than to other trauma patients [5]. High-volume burn centers often accept these infectious burn patients from lowvolume centers after the third day of injury. Such patients are counted as in-hospital survivors in the lowvolume centers, which may contribute to their lower inhospital mortality rates, lower healthcare costs, and higher number of hospital-free days.

In summary, the data and statistical analysis used in this study were adequate, but there were potential biases due to the transfer and selection of severely injured patients. Bias can originate from the "transfer out" of patients and selection bias due to choosing patients with a severe systemic condition who might affect survival within 2 days (these patients would be admitted more often to high-volume burn centers), which was not accounted for by the risk adjustment based on burn severity. This is why the discrepancy between the original analysis in Figure 2 and the sensitivity analysis in Figure S7 appears to be so obvious. Further data on hospital center-level transfer rates could be obtained by supplementing the data with sensitivity analyses of transfer rates. We suggest that an appropriate sensitivity analysis to visualize these potential biases requires the following to be performed: (1) remove both the patients who were transferred in from outside the institution and those who were transferred out (so these patients cannot be counted in the survival figures) and (2) exclude patients who died within 2 days as the quality of burn care would be best reflected by the care administered to those patients who survive more than 2 days. This analysis would account for the initial severity of illness that reflects the imminent risk of death, for example, carbon monoxide or cyanide poisoning or cardiac arrest on the scene.

In conclusion, from the setting of this study, the authors cannot conclude that high burn patient volume was significantly associated with an increase in inhospital mortality.

\section{Acknowledgements}

Not applicable.

Authors' contributions

$\mathrm{AO}$ designed the manuscript and wrote the first draft. The other authors revised the manuscript, and all authors read and approved the final manuscript.

\section{Funding}

Not applicable.

Availability of data and materials

Not applicable.

Ethics approval and consent to participate

Not applicable.

Consent for publication

Not applicable.
Competing interests

The authors declare that they have no competing interests.

Received: 3 April 2020 Accepted: 15 June 2020

Published online: 08 July 2020

References

1. Endo A, Shiraishi A, Otomo Y, Fushimi K, Murata K. Volume-outcome relationship on survival and cost benefits in severe burn injury: a retrospective analysis of a Japanese nationwide administrative database. J Intensive Care. 2019;7:7.

2. Harish V, Raymond AP, Issler AC, Lajevardi SS, Chang LY, Maitz PK, et al. Accuracy of burn size estimation in patients transferred to adult burn units in Sydney, Australia: an audit of 698 patients. Burns. 2015;41:91-9.

3. Jeschke MG, Pinto R, Kraft R, Nathens AB, Finnerty CC, Gamelli RL, et al. Morbidity and survival probability in burn patients in modern burn care. Crit Care Med. 2015:43:808-15.

4. Gutzler L, Schiestl C, Meuli M, Oliveira C. Toxic shock syndrome in paediatric thermal injuries: a case series and systematic literature review. Burns. 2018; 44:e1-12.

5. Mann EA, Baun MM, Meininger JC, Wade CE. Comparison of mortality associated with sepsis in the burn, trauma, and general intensive care unit patient: a systematic review of the literature. Shock. 2012;37:4-16.

\section{Publisher's Note}

Springer Nature remains neutral with regard to jurisdictional claims in published maps and institutional affiliations. 